\title{
Support systems. 2. Staff sensitivity groups
}

\author{
Rex Haigh
}

It is deeply satisfying to all mankind that many ailments, once dangerous, mysterious and worrying, now offer the therapist of today wonderful opportunities for the exercise of his skill; but with recalcitrant distress, one might almost say recalcitrant patients, treatments tend, as ever, to become desperate and to be used increasingly in the service of hatred as well as love; to deaden, placate and silence, as well as to vivify. (Main, 1957, in The Ailment)

\section{Why have staff sensitivity groups?}

Difficult interactions with patients leave us with subjective experiences that are often unpleasant. We feel things - for example, frustrated, inadequate or angry. Our own individual make-up is one factor which determines the nature and intensity of the feelings generated. Others are the patient's psychopathology (borderline personality disorder is notorious in producing emotional responses in professionals), and the context we are working in (five minutes contact in a ward round is different from an hour of long-term psychotherapy). As a result of this inevitable process, we can act on these feelings directly, deny them any conscious relevance, or try to understand them. If we act on them directly, we run a high risk of acting unprofessionally; if we deny them any conscious relevance, we cannot be certain that they do not introduce bias into our clinical decisions; if we discuss them in a way to understand them, they might provide an educational opportunity through which our practice can subsequently improve.

This forms the basis of the experimental work discussion group set up by Main at the Cassel Hospital and described in The Ailment (Main, 1957). After two staff suffered clinical breakdowns, and others showed signs of severe strain, Main met with the senior nurses and arranged to set up a twiceweekly group to make a retrospective study of a dozen patients whom they considered to be 'major failures'. The instrument of a group (perhaps a 'focus group' in modern qualitative research parlance), rather than a more direct method, seems to have been necessary to undertake sufficient depth of exploration:

"Only a group could achieve the capacity to recall past events with the merciless honesty for detail and corrections of evasions and distortions that this one required from and tolerated in its members".

He notes that, as well as making a helpful analysis of the failures they had identified, the staff emerged with an increased capacity to recognise insincerities in their daily work and felt personally easier in it, less afraid of difficult situations and surer at their craft.

Few psychiatrists in the National Health Service (NHS) 40 years on would deny the importance of working in, or at least with, teams. Imperatives for this are all around us in our professional lives; from official inquiries about poorly functioning teams, such as Ashworth (Fallon, 1999), and NHS policy documents about the way we need to work in a

Rex Haigh trained in general practice in the West Country, where the small group work that was part of the training started an interest he has pursued since. He subsequently trained in psychiatry in Oxford, psychotherapy in Birmingham and group analysis in London. He has been a consultant psychotherapist in West Berkshire since 1994, where he is responsible for a day care therapeutic community, which is run as part of a district psychotherapy service. He is Chair of the Association of Therapeutic Communities and treasurer of the UK Chapter of the Society for Psychotherapy Research. He is also a member on College Council, and programme director for the Oxford regional higher training in psychotherapy 
modern mental health service (NHS Executive, 1999) to theoretical papers about attachment patterns at work (Adshead, 1998). I have argued elsewhere that the qualities of a therapeutic environment - for example, the importance of developmental experiences such as attachment, containment, communicative openness, involvement and personal agency are relevant considerations for staff as well as patients (Haigh, 1996). Pullen has gone further, and argues that a primary function of a working environment for 'difficult' patients is to provide something that is therapeutic for staff, to enable them to do their best work (Pullen, 1999).

The group that Main set up was perhaps a luxury in terms of time and resource devoted to detailed scrutiny of a single issue, but accumulated experience of using groups to enhance functioning in mental health teams means that we can now state with some confidence the ways in which staff groups should be set up, and what they should not be expected to do.

\section{Relationships in teams}

The word 'team' implies relationships between its members. The behaviour in those relationships is the responsibility of each individual, and the experience of them is unique for each individual. But the quality of those relationships, which can be seen as a function of the behaviour and experience, has a direct bearing on the effectiveness and ultimate productivity of the team. In an extreme case of a dysfunctional team, untrusting or openly hostile relationships between members can mean that individuals experience little satisfaction or fulfilment from their membership, and are less effective at work than they could be. Alternatively, a team where members are open with each other in their relationships - allowing and discussing conflict, for example - is likely to be a positive experience which makes for easier negotiation of stress and difficulty, reduces blocks to creative thinking, and thus increases productivity.

Important issues in teams are power, authority and leadership. In teams of professionals, it is rarely solved by a simple hierarchical relationship between members, but needs negotiation and understanding by those with more power and responsibility as well as those with less. There are similar and equally complex issues about relationships between different professionals who have different tasks or roles within a team. Such issues are likely to bring to bear personal feelings about being in charge, or being under the charge of others. These may be acted on overtly (e.g. disobedience or overbearing manner) or outside awareness (e.g. poor performance or increased rates of sick leave). When aspects of these dynamics are safely addressed, it can help the structure of leadership in a team to be made manifest, and possibly also help to define and secure the team's relationship to the superordinate structures upon which its functioning depends.

Without a forum to talk together, a team cannot experience a sense of identity. In this case, several processes which work against good team functioning are likely to develop. These are akin to Bion's (1959) 'basic assumptions' and reflect primitive mental functioning, where the environment is made safe by using defensive actions to avoid psychic pain. The psychic pain may be inherent in the work (such as dealing with great human misery) or arise from relational tensions (such as preferring the comfort of a collusive denial to exposure to anger and conflict). Examples are splitting, subgrouping, secrets, scapegoating, dependence and isolation. Put simply, without an effective staff group, things can go underground and never be understood in a productive way. An 'us and them' mentality can predominate.

If they are set up carefully, staff sensitivity groups (SSGs) can be used in a team to enhance understanding of the relationships between members and promote a more cohesive and coordinated way of working. Used inappropriately, or imposed without the necessary sanction or clarity of purpose, they can expose or exacerbate uncontainable tension and lead to overt fragmentation and discord.

Box 1 gives a summary of reasons for teams to have SSGs. These are more working hypotheses than facts: there is little robust evaluation or evidence of effectiveness. What has been written about SSGs is descriptive, and often theoretical. Most advise great

Box 1. Possible benefits of having an SSG

Improved morale, less burn-out Sense of safety and containment at work Greater understanding of others' roles and responsibilities

Enhanced open communication

Prevention of destructive subgrouping

Power, leadership and hierarchy issues can be addressed

Better relationships between staff

Playfulness and creativity in a team are encouraged 
caution about setting up such groups, as they are often wrongly seen as a panacea for problems they are not designed to address. For example, Bramley (1990) writes of her experiences as a group analyst, and Milton \& Davison (1997) compare two different staff groups from a psychoanalytic perspective. Bramley urges prospective conductors to consider the complexity of the system in which such groups operate. She warns that a conductor might be a sitting target for "organisational paranoia, idealisation or contempt". Milton \& Davison compare a 'successful' staff group in a community mental health team (CMHT) with one on a locked ward, which the participants found alienating and destructive. They examine how the primitive anxieties generated in the difficult group could be related to uncontainment of "unbearable states of mind", and how the more successful one could operate as what Bion (1959) called a 'work group'.

\section{Different types of staff group}

An SSG is not a therapy group, nor a staff support group, nor a Balint group, nor a chance to have coffee together regularly. Sensitivity training groups, which address specific insensitivities, are also clearly different. There are similarities with training groups (t-groups), but membership is different. An SSG is not a venue for making clinical decisions about patients' treatment, nor for formulating or implementing administrative and managerial policies - although it may have an indirect effect on these. These different types of staff group will each be considered in turn, to distinguish them from SSGs.

An SSG differs from a therapy group in that feelings discussed are related to the task of work about patient care, and how relationships between staff impinge on it. It is not concerned with the personal histories and emotional development of members of staff, as a therapy group would be. Current life events of staff, such as bereavement, moving house or leaving the job, may be relevant (much as they would in a therapy group), but the task of the sensitivity group is to reflect upon the impact such events have on the work in hand, through the relationships in the staff team. Sometimes, it becomes clear in an SSG that a member is not coping and needs other help. In these circumstances, the team should not try to undertake the therapy itself in the sensitivity group. If it is functioning well, the relationships within the team are such that somebody could guide the person in difficulties in the right direction - and probably not during the group itself.
'Balint groups' are dynamic work discussion groups with the doctor-patient relationship as the focus (Balint, 1964). They lead to a deeper understanding of patients' psychopathology and, as Balint himself noted, sometimes also a "small but significant" change in the personality of the doctor himor herself. In the original experiment they were for general practitioners (GPs), who came along to the sessions with a handful of the brown 'Lloyd George' record envelopes of the patients they wished to discuss and understand. The participants did not work together as a team outside the discussion seminar. So, although they observed and reflected upon their own dynamics, the work was primarily in the service of clinical supervision, and not to understand and use relationships within a practising team. Developments of these sorts of group since Balint - such as those for psychiatric registrars to discuss dynamic aspects of their ward patients make this distinction less clear (in that they have a working relationship outside the seminar group), and these are often called 'work discussion groups'.

An example of a staff support group is one in a hospice, where staff meet regularly to discuss stressful aspects of the work and to debrief. These groups do overtly use exploration of relationships within the team, or scrutiny of their own process. As support groups develop a working culture, developing relationships and group dynamic processes can start to be used, and have useful spinoff benefits, but they are not the declared purpose of the group. Lederberg (1998) has reviewed staff support groups and the need for them in response to the development of 'modern medicine'. This includes increased patient expectations, a perceived loss of humanity in caregivers, a number of technical and regulatory demands, increasingly public scrutiny of ethical conflicts, and insecurities of employment through frequent organisational change. As in other types of staff group, she notes that the methodology of study of these groups to date is not rigorous. Her paper describes goals for such groups, how they develop and requirements of leadership style.

A sensitivity group must guard against becoming a primarily social function, where staff meet together regularly perhaps to drink coffee or tea, gossip and joke together. Informal time to meet is important in a team, but an SSG should be in addition to it, not instead of it. If a scheduled group becomes 'social', it loses its power of critical scrutiny (Main's "merciless honesty") - which could be described as resistance - in choosing the easier options of avoidance of conflict and hard mental work, and collusion in that avoidance. The easiest way to prevent "drift into sociability" is to have an external facilitator. However, it is important that an SSG is 
not a wholly ascetic experience, devoid of any playfulness, warmth or laughter. If an SSG is seen as an earnest, sombre and heavy occasion where only deep and difficult feelings are discussed, it will be very difficult to get any staff to go to it!

'Sensitivity training groups' are groups with the defined task of making members aware of their need to be sensitive to specified psychosocial factors. Examples are human immunodeficiency virus (HIV), racial, gender, religious or sexuality awareness training. Groups are directively conducted, with conductors who have specific expertise and knowledge of the area. Other outsiders may also contribute, such as people with HIV infection in HIV awareness training, or Asian and Black participants if the task is training for sensitivity to racial issues. The aim is for participants to overcome some deeply held ideas by understanding that they are prejudices, and by demystifying the sense of 'otherness' that lies behind prejudicial thinking and behaviour. They work with a defined area of concern, may include clinical material, but do not generally have the task of looking at their own functioning.

'T-groups' do not involve members of the same team, and it is helpful if they are composed of strangers. The task is to understand aspects of group dynamics by the group itself examining how it functions: there is no necessity to bring clinical or personal material, although it may happen. The style of conducting has a major impact on the sort of dynamic processes that emerge: a conductor who sees his or her function as only making group-level interpretations will set up a group which focuses on an analysis of Bion's basic assumptions. In contrast, a conductor who works in a Foulksian way (Foulkes, 1964) to provide a safe and facilitative space for exploration of relationships will give less opportunity for immersion in primitive dynamics, but will encourage a nurturant, challenging and possibly playful intersubjective experience if successful.

'Supervision groups' have clinical material as their focus: reflection about the process of therapy and trying to achieve a useful understanding of it are the aims. A better term for supervision, which has directive overtones, might be 'clinical reflection'. The importance of reflective practice is increasingly recognised, for example as part of continuing professional development (CPD) and it can be enriched by doing it transprofessionally. The task of such groups might include making clinical decisions about specific issues. They occasionally examine the relationships between members of the supervision group, but only in so far as these may cast light on the therapy being supervised. This may particularly apply to co-conductors of therapeutic groups being supervised in a group format.
A 'consultation group' is formed at the invitation of a person or group who has sanction, power and resources (such as money or staff) to implement change. The changes are managerial in nature (such as allocation of resources or roles). The external conductor of such a group essentially collects data from the group - which may include information about the relationships between its members, and between them and the wider organisation - and advises the client (somebody with managerial responsibility) on changes in the organisation. These groups vary from being one-off exercises, possibly away-days for several hours, to regular meetings over a period of weeks or months. In contrast, an SSG has the aim of understanding its own functioning, and not directly recommending change. Change may, however, come about through indirect influence of SSGs.

\section{What is required to set up an SSG?}

In order to function as a safe space in which people can talk, an SSG needs to have an explicit membership, a regular scheduled meeting time, a comfortable space and an external facilitator.

The membership should include all those who spend time working together, and is ideally transprofessional. Examples of suitable membership are all the staff working with patients on an adolescent unit; community psychiatric nurses, social workers, consultants and junior doctors in a community mental health team; and all the staff and support workers in a rehabilitation ward. The lowest working membership size of such a group is about four or five, and the upper limit 20 or 30 . Teams less sophisticated in using groups are unlikely to be able to tolerate and use larger group sizes.

Single-discipline sensitivity groups are not going to be able to explore inter-disciplinary tensions and may find external scapegoats for their dissatisfactions through a process of splitting and projection ("We've a different job to the managers/doctors / nurses and they don't understand what it's like; they're responsible for the problems"). The same projective processes can happen if the leader of a team, or the most senior clinician, is not a member.

It is important to define and explain exclusions to membership before starting, otherwise those whose involvement with the team is more peripheral may be unhelpfully alienated. Some common questions are: should students (for example, on four-week placements) attend? Are clerical staff who deal directly with patients to be included? Should the 
line manager be invited? Are sessional workers who are very part-time counted as members of the team? These decisions should made with practical considerations, and sometimes the individuals concerned, in mind. Clarity of membership, and openness about it, is the aim.

The timing and format of SSGs can vary considerably. They can be weekly, fortnightly, monthly, termly, twice a year or annually. The less frequent ones need to be of longer duration. Common patterns are one hour weekly, 90 minutes fortnightly, half a day quarterly, one day twice per year or two days residential annually. The total time of all these is between 2 and $4 \%$ of total working time.

When an SSG starts, it can be set up to run indefinitely, for a fixed number of sessions, or with a review after an agreed period. For open-ended groups, it can also be helpful to consider changing the format, facilitator or style cyclically - perhaps every two years - although this can emerge from discussions in the group itself.

The space in which a sensitivity group takes place needs to be large enough to comfortably accommodate all the members on approximately equivalent seats, although some groups prefer the style of sitting on cushions or the floor. It is necessary for everybody to see and hear each other as they talk, so members are usually in a circle. If at all possible, all interruptions must be prevented. This includes mobile telephones, bleeps and other staff coming in with messages. Members need to be made aware of the 'protected time and space' in which the group exists. Once established, it generally becomes second nature, and punctuality in beginning and ending follows.

The facilitator needs to be somebody who is experienced as neutral to all members of the group in other words, not known to them in other capacities. A facilitator should have experience and training in using groups, and ideally special expertise in conducting staff groups. The leader of

Box 2. Requirements for an SSG

Clarity of membership

External facilitator/conductor

Protected time, regular schedule

Uninterrupted and comfortable venue

Shared idea of purpose (i.e. it is not therapy or a business meeting)

Commitment from participants

Interdisciplinary (desirable)

Including management (desirable) the team, or a close colleague or personal friend of one of the staff, would not be able to conduct the group with the required objectivity.

\section{Problems and pitfalls}

What little has been written about staff groups, and SSGs in particular, urges caution: "No danger warnings in an ill-charted minefield" (Bramley, 1990). And there is the familar therapeutic paradox: the team with a well-functioning SSG is likely to be the team that least needs one. A solution, as in psychotherapy, is to see the main problem as engagement: the equivalent of forming a good therapeutic alliance.

This implies that the hard work in having an SSG is getting to the starting line in fit shape to start after that the group itself is comparatively straightforward. The responsibility for having the idea, making the decision to proceed, and doing the practical work to get it going should be shared in a way that may not be possible until after the group is running. A minimum would be for the whole team to discuss their reasons for having an SSG, air their hopes and fears for it, and for everyone to be very explicit about what it is not (this specifically means therapy, supervision, unit business or social time).

Problems are likely to be encountered later if senior professional staff and managers are not involved. On a ward, this means at least the consultant, senior nurses and ward manager; the ward manager should also be doing it with the support and understanding of his or her line manager. Membership needs to be crystal clear: an example is all clinical staff on the unit for more than six months working more than half the week.

It has been said that groups live or die by their boundaries, and nowhere is this more true than in SSGs. As Bramley (1990) says:

"Boundaries are so much more fudged than those of the conventional therapy group. There is no selection, assessment or preparation of participants. They meet outside the group. The group is part of a bigger group which cannot and must not be ignored..."

When such a group starts, and until members appreciate that respect for the boundaries equates with respect for the relationships in the group, and thus for each other, boundary testing occurs in a multitude of different ways: the senior house officer might be a bit late each week because the path lab needs samples in before lunch; a couple of nurses might have to leave 10 minutes before the end to give the medications on time; the unit might be 
hosting important meetings in that room on two Mondays in the group's first month; "I hope you don't mind me bringing my coffee in - I haven't had a break yet"; "The cat's just had kittens"; "The managers' meeting over-ran"; "The consultant's secretary just phoned and he hopes to get here before the end..."

More invidious and destructive are the 'macho' attitudes that some staff hold and maintain in subgroups. Typically, these are that work is not something that generates feelings or needs, and certainly not feelings that would be helped by talking to others about them. These people are likely to see it as a sign of weakness to attend SSGs or find benefit from them. This level of denial is often difficult to influence, and when it exists in senior staff a successful sensitivity group is unlikely to get off the ground. Sometimes, it might be useful to confront it directly, before the group starts, and use managerial authority to force attendance. This makes any split clearly visible, and if well-contained in the group, could form the basis of fruitful work. Another option would be to compromise with an 'agree to try it and see how it goes' arrangement. In either of these cases, the resistance should not then be left unspoken in the group, lest it go underground and lead to a nucleus of staff who silently resent the group. The same outcome would be likely, with a split team, if staff members were allowed to opt out of the group entirely.

Conductors are very variable in style, approach and theoretical background. They may also be very skilled and professional, or less than fully competent. A conductor who remains entirely opaque and makes occasional plunging interpretations is unlikely to make a staff group feel at ease with itself: such a style would be more suited to a t-group. At the other extreme, an overzealous conductor who agrees how difficult it is to work under the pressure the group members are under, and thinks that something should be done about it, is not going to have the necessary impartiality. Bramley (1990) is clear about what makes a good conductor: he or she needs a sound training, and a well-developed capacity to wait and see: to tolerate ignorance of the long-established culture into which the conductor is a transient visitor without rushing in with answers, diagnoses or interventions.

It follows that an important task before starting an SSG is to choose the conductor: like many aspects of the group, it is worth getting it right before starting, rather than trying to sort out incompatibility problems once a contract is in place. First, an idea of what approach is wanted needs to be generated by the staff team. Then, advice needs to be sought from colleagues who know about relevant group trainings and qualifications; this might be from a psychotherapy department, or another clinician with knowledge of groups. Otherwise, reputable psychotherapy training institutions can often make recommendations of whom to approach. Selection is important, and needs to incorporate an informal 'meet the team' component, so they can ask questions and get an idea of how the group conductor would propose to work with them. The best formal arrangement is probably a fixed-term contract with a built-in review date or review process, so either side can discontinue if they feel the need to. An identified staff member needs to be recognised as the negotiator with the conductor, so that all communications about pay and terms of engagement go through one person. Ideally (although in practice this is often impossible), this person should not be a member of the group itself.

\section{Getting the evidence}

Anecdotal experience - such as the observations that dysfunctional teams almost never have SSGs and most teams that do have them seem to have a clear team identity - strongly suggests that there may be value in such groups. However, as Milton \& Davison (1997) conclude, there are important and urgent questions that need rigorous scrutiny. Further study on SSGs, both clinical and empirical, is needed to consider the questions:

- Do they work?

- What happens in them?

- What are the essential ingredients?

"Do they work?" is the type of question only answered unequivocally by a randomised controlled trial. Such a study would be relatively easy to set up. A pilot would be of two matched units, one being randomly allocated a long-term SSG. Outcome

Box 3. Problems in SSGs

Trying to be a different type of group

Set up for wrong reasons

Key staff not involved (e.g. leaders)

Unclear membership criteria

Poor boundary maintenance

Discontinuity of attendance (shifts, etc.)

Culture of toughness

Sabotage, boycotting, destructive avoidance

Overactive conductor (plunging interpretations or overzealous activity) 
measures could be staff sickness, staff turnover, adverse incidents and staff morale. The definitive study would need to be large to have sufficient power for a 'groups make no difference' null hypothesis to be proved.

"What happens in them?" is a qualitative question. It must be asked because, with current understanding, the term 'staff sensitivity group' means different things to different people. This study would be a rigorous and scientific description of different such groups, identified by consensually agreed criteria, using ethnographic research methodology (Hammersley \& Atkinson, 1995). Data collection would be by non-participant observation, tape- or video-recording and field notes. Analysis would be guided by the data as they emerge. A step further would be to use grounded theory, where generalisable theoretical constructs are generated on the basis of the data and their preliminary analysis (Strauss \& Corbin, 1990).

"What are the essential ingredients?" could be answered by path-analytic causal modelling, using structural equations to relate variables. This is a technique that measures several process variables as well as the outcome ones mentioned above. Relevant variables would need to be agreed and their number kept quite small in order for the statistical analysis to have sufficient power. Examples would be type of unit, frequency of group meetings, attendance figures at meetings, training and experience of conductor, and maintenance of boundaries. The analysis is represented by a flowchart, with arrows between the different process factors and the outcomes, with different 'strengths' of arrow for different strengths of causal evidence. A hierarchy of the most important factors and the relationships between them could then easily be generated. The technique has been used successfully in therapeutic communities (Lees \& Manning, 1985).

\section{Conclusion}

This paper has attempted to draw together elements of best practice as published and taught in the group psychotherapy field. Most of us would acknowledge that there is something very important about belonging to a well-functioning team and that it can make our work more productive. It is also a gratifying experiencing in its own right that may well be related to meeting primitive needs for attachment and inclusion. The next task is to open the field to the rigorous scrutiny that accountability and transparency demand. Some well-designed studies need to be set up, possibly along the lines explored above. The economic consequences of effective prevention of dysfunctional teams could be much wider than in the mental health field alone: staff groups are used in many settings, without robust evidence of their effectiveness. On the other hand, if research proves such groups (or certain types of them) to be ineffective, then we could save ourselves much time and wasted work.

\section{References}

Adshead, G. (1998) Psychiatric staff as attachment figures. British Journal of Psychiatry, 172, 64-69.

Balint, M. (1964) The Doctor, His Patient and The Illness (2nd edn). London: Pitman.

Bion, W. R. (1959) Experiences in Groups. London: Tavistock.

Bramley, W. (1990) SSGs: a conductor's field experiences. Group Analysis, 23, 301-316.

Fallon, P. (1999) Report on the Committee of Inquiry into the Personality Disorder Unit, Ashworth Special Hospital. London: Stationery Office.

Foulkes, S. H. (1964) Therapeutic Group Analysis. London: Allen \& Unwin.

Haigh, R. (1996) The ghost in the machine: the matrix in the milieu. In Contemporary Psychology in Europe: Theory, Research and Application (eds J. Georgas et al), pp. 288302. Gottingen: Hogrefe \& Huber.

Hammersley, M. \& Atkinson, P. (1995) Ethnography: Principles in Practice (2nd edn). London: Routledge.

Lederberg, M. S. (1998) Staff support groups for high stress medical environments. International Journal of Group Psychotherapy, 48, 275-304.

Lees, J. D. \& Manning, N. (1985) Australian Community Care: a Study of the Richmond Fellowship. Canterbury: University of Kent. Findings in Manning, N. (1989) The Therapeutic Community Movement: Charisma and Routinisation. London: Routledge.

Main, T. F. (1957) 'The Ailment'. British Journal of Medical Psychology, 30, 129-145.

Milton, J. \& Davison, S. (1997) Observations of staff support groups with time-limited external facilitation in a psychiatric institution. Psychoanalytic Psychotherapy, 11, 135-143.

NHS Executive (1999) A National Service Framework for Mental Health. London: NHS Executive.

Pullen, G. (1999) Schizophrenia: hospital communities for the severely disturbed. In Therapeutic Communities: Past, Present and Future (eds P. Campling \& R. Haigh), pp. 148149. London: Jessica Kingsley.

Strauss, A. \& Corbin, J. (1990) Basics of Qualitative Research Grounded Theory Procedures an Techniques. London: Sage.

\section{Multiple choice questions}

1. Tom Main's study, published as 'The Ailment':

a was qualitative research

b was a randomised controlled trial

c described the dynamics of staff splitting

$\mathrm{d}$ had little impact on nursing staff

e was based on psychoanalytic ideas.

2. SSGs usually address issues such as:
a disagreements in the team
$\mathrm{b}$ authority and power
c patients' psychodynamic formulations
d staff members' own troubled childhoods
e staff arrivals and leavings. 
3. Balint groups:

a were originally set up for GPs

$\mathrm{b}$ are only for personal issues

c can include decision-making about management issues

d are primarily for people who work together

e psychoanalyse doctors who participate.

4. The following are important in setting up an SSG:

a plentiful supply of tea and coffee

b a conductor who knows all the staff

c protected time and space

d clear criteria for membership

e excluding managers.

5. The following would be most helpul in advancing knowledge and understanding of staff groups:

a randomised control trials

b ethnography c questionnaire surveys

d grounded theory

e descriptive accounts.
MCQ answers

$\begin{array}{lllll}1 & 2 & 3 & 4 & 5\end{array}$

a $\mathrm{T}$ a $\mathrm{T}$ a $\mathrm{T}$ a $\mathrm{F}$ a $\mathrm{T}$

$\begin{array}{llllll}\text { b } F & \text { b } T & \text { b } F & \text { b F } & \text { b } T\end{array}$

$\begin{array}{llllllllllll}\text { c } & T & \text { c } & F & \text { c } & T & \text { c } & T & \text { c } & F\end{array}$

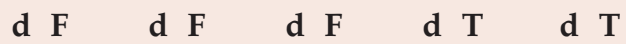

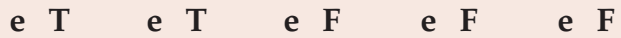

\section{Assessing Forensic Mental Health Need: Policy, Theory and Research \\ Andrea Cohen and Nigel Eastman}

Mentally disordered offenders (MDOs) have dominated the recent political agenda for mental health care emphasised by cases such as those of Christopher Clunis and Michael Stone. Yet successive governments have constrained the development of all health and social services by the requirement that they must be demonstrated as capable of benefiting those to whom they are applied.

This book analyses the development of government policy for services for MDOs since the important Butler report in 1975 and provides a theoretical framework for adjudging research which purports to demonstrate a need for MDO services of various types. It also provides a comprehensive review of relevant empirical research and addresses the important links between need and outcome. Finally, it emphasises the subjective and value-laden nature of all needs assessments and their interpretation and poses the crucial question of whose need it is that we address through MDO services, those of the patient or of society.

This book will be valuable to clinicians and researchers working in mental health services, policymakers, service commissioners and managers.

Andrea Cohen and Nigel Eastman work in the Mentally Disordered Offender Policy Research Unit at St George's Hospital Medical School.

June 2000, hardback, £30.00, ISBN 1901242420

Booksales, The Royal College of Psychiatrists, 17 Belgrave Square, London SW1X 8PG Telephone +44 (0)20 72352351 ext. 146; fax +44 (0)20 72451231

http://www.rcpsych.ac.uk 